\title{
Seeding metastases: The role and clinical utility of circulating tumour cells
}

\author{
Deep A. Patel ${ }^{\mathrm{a}}$ and Jonathan Blay ${ }^{\mathrm{a}, \mathrm{b}, *}$

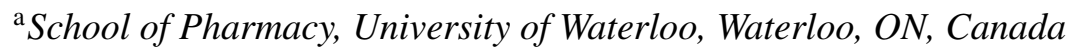 \\ ${ }^{\mathrm{b}}$ Department of Pathology, Dalhousie University, Halifax, NS, Canada
}

Received 11 March 2021

Accepted 26 July 2021

\begin{abstract}
Peripheral human blood is a readily-accessible source of patient material in which circulating tumour cells (CTCs) can be found. Their isolation and characterization holds the potential to provide prognostic value for various solid cancers. Enumeration of CTCs from blood is becoming a common practice in informing prognosis and may guide therapy decisions. It is further recognized that enumeration alone does not capture perspective on the heterogeneity of tumours and varying functional abilities of the CTCs to interact with the secondary microenvironment. Characterizing the isolated CTCs further, in particular assessing their functional abilities, can track molecular changes in the disease progress. As a step towards identifying a suite of functional features of CTCs that could aid in clinical decisions, developing a CTC isolation technique based on extracellular matrix (ECM) interactions may provide a more solid foundation for isolating the cells of interest. Techniques based on size, charge, density, and single biomarkers are not sufficient as they underutilize other characteristics of cancer cells. The ability of cancer cells to interact with ECM proteins presents an opportunity to utilize their full character in capturing, and also allows assessment of the features that reveal how cells might behave at secondary sites during metastasis. This article will review some common techniques and recent advances in CTC capture technologies. It will further explore the heterogeneity of the CTC population, challenges they experience in their metastatic journey, and the advantages of utilizing an ECM-based platform for CTC capture. Lastly, we will discuss how tailored ECM approaches may present an optimal platform to capture an influential heterogeneous population of CTCs.
\end{abstract}

Keywords: CTC, metastasis, EMT, integrins, ECM adhesion

$\begin{array}{ll}\text { Abbreviations } \\ \text { CK } & \text { cytokeratin } \\ \text { COPD } & \text { chronic obstructive pulmonary disease } \\ \text { CSC } & \text { cancer stem cell } \\ \text { CTC } & \text { circulating tumour cell } \\ \text { ECM } & \text { extracellular matrix } \\ \text { EMT } & \text { epithelial-mesenchymal transition } \\ \text { EpCAM } & \text { epithelial cell adhesion molecule } \\ \text { HSC } & \text { hepatic stellate cell } \\ \text { MET } & \text { mesenchymal-to-epithelial transition } \\ \text { MMP } & \text { matrix metalloproteinase } \\ \text { RTK } & \text { receptor tyrosine kinase. }\end{array}$

\footnotetext{
*Corresponding author: Jonathan Blay, School of Pharmacy, University of Waterloo, 200 University Ave. W., Waterloo, Ontario, N2L 3G1, Canada. Tel.: +1 5198884567 /Ext: 21375; Fax: +1 519883 7580; E-mail: jonathan.blay@uwaterloo.ca. 


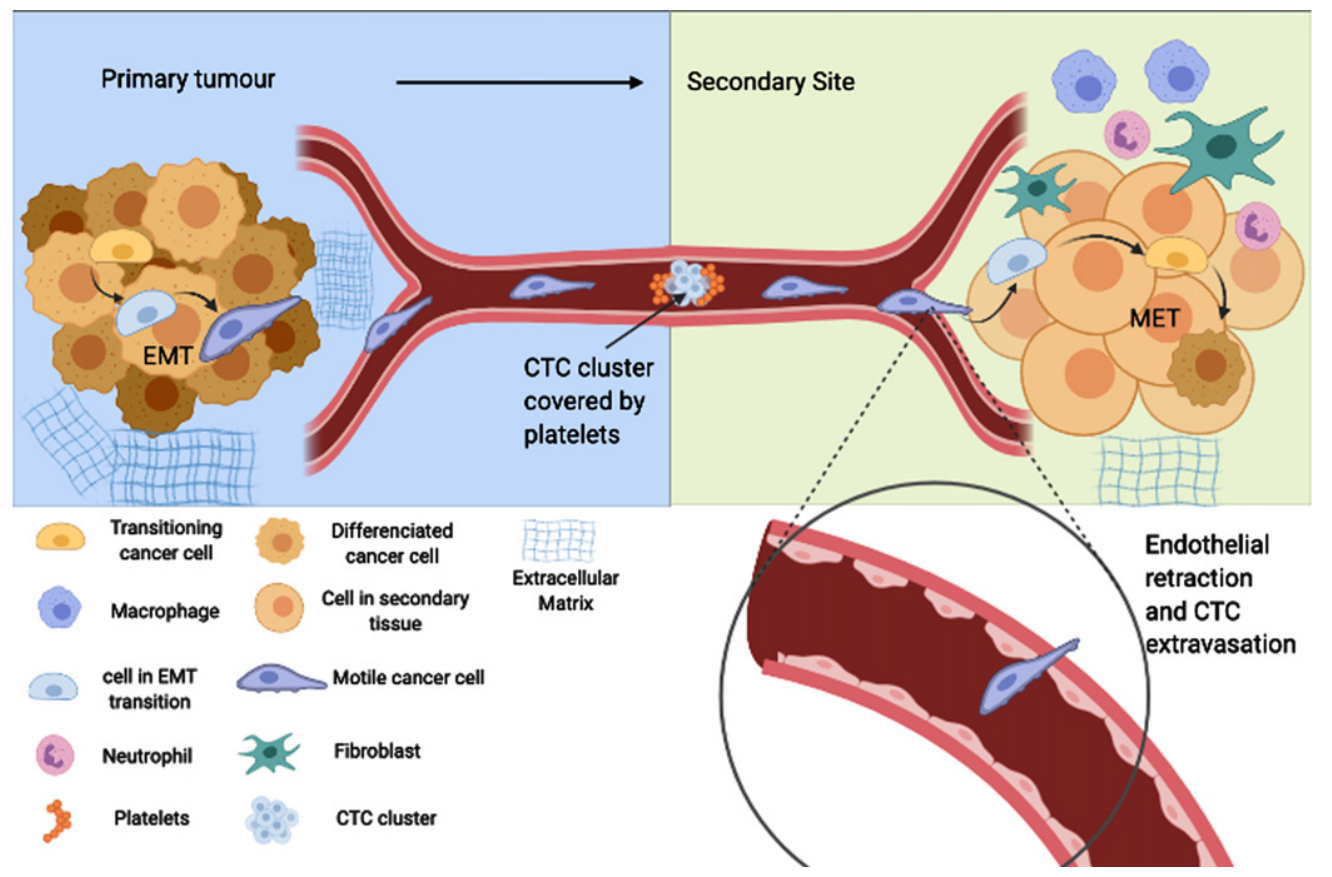

Fig. 1. Principal features of the metastatic process in solid cancers. This schematic diagram shows cells as they undergo (i) epithelial to mesenchymal transition (EMT), (ii) circulation through the bloodstream as single cells or clusters and (iii) the reverse process of mesenchymal to epithelial transition (MET) required before (iv) cells establish distant site metastases. (Adapted from [187]; created with Biorender ${ }^{\mathrm{TM}}$ ).

\section{Introduction}

The term 'precision medicine' is often used these days within oncology and its central idea is to identify and provide patient-centered therapies in cancer. One of the tools under precision medicine is liquid biopsy [1], which the National Cancer Institute, United States defines as "a test done on a sample of blood to look for cancer cells from a tumour that are circulating in the blood or for pieces of DNA from tumour cells that are in the blood" [2]. Indeed, blood samples from cancer patients can be utilized as a source of the individual tumour cells in circulation [3], clusters of tumour cells [4-8], pieces of tumour DNA [9], microRNAs [10], exosomes [11], and plasma chemokines [12].

In 1869, Ashworth first reported cells found from an individual's blood that resembled cells from that patient's tumours [13]. Following that, in vivo studies beginning in the mid-20th century further showed that circulating tumour cells (CTCs) can be detected in the general circulation during the natural progression of solid tumour growth - even prior to detecting established metastases [13, 14]. This area of research is crucial as it is estimated that $\sim 90 \%$ of human cancer deaths are caused by tumour invasion and metastasis $[15,16]$. Cells evolve as the disease develops and enable its progression. Some of the phenotypic changes that tumour cells undergo as they make their journey from primary carcinoma to a secondary site to form a metastasis are shown in Fig. 1.

In the following sections, we will consider some of the essential characteristics that enable cells from the primary tumour to gain an invasive phenotype and survive in the peripheral blood circulation, current techniques in isolating and characterizing circulating tumour cells, and the idea of functional capture of circulating tumour cells using extracellular matrix interactions. 


\section{Considerations in the journey of cells from a solid carcinoma to a metastatic site}

The journey of cancer cells from the primary to the secondary site is a challenging process with many rate-limiting steps. It is no more than approximately one cell out of billions that fully possesses or acquires true metastatic potential, developed through natural selection after genetic changes during tumour formation, and persists in the hostile environment of blood to eventually reside and be capable of self-renewal at a favorable secondary location.

The monoclonal theory of cancer origin recognizes that a single cell may be responsible for neoplasms that lead to malignancy [17]. The transformation in this single cell may not be immediate, but requires multiple rounds of proliferation to execute the underlying genetic changes [18]. Imbalance in proliferation is one of the vital changes that is marked in the process of carcinoma development. There are different pathways and molecules at play during this aberration. They can involve autocrine production of certain mitogens, or mutations in receptor tyrosine kinases (RTKs), or G-protein signal transducers like Ras [19]. Dysregulation of proteins like p53 and retinoblastoma protein (pRB) is also common in many cancers and leads to erratic proliferation [19, 20]. As proliferation leads to the expansion of a tumour, the cells that are further away from blood capillaries struggle to obtain oxygen and nutrients due to the increased distance [21]. Oxygen sensor enzymes PHD and FIH-1 stabilize HIF-1 $\alpha$ protein triggering downstream effects including new blood vessel formation [21].

Hanahan and Weinberg defined multiple key hallmarks of cancer that help us understand its unique features - being able to resist cell death, induce proliferative signalling, gain immortal replication potential, reprogram energy metabolism, induce angiogenesis, evade the immune system and growth suppressors, and activate invasion and metastasis [22, 23]. A cell lineage that has gone through successive genotypic and phenotypic transformations can yield an immortal cancerous cell with the characteristics listed above [24]. As a result of the continuous replicative potential and other hallmark characteristics, colonies of a cancerous cell are able to grow in the local environment. Where a colony of cancerous cells is confined in a limited local area, it is referred to as carcinoma-in-situ [2]. The confining boundary acts as a rate-limiting step in the progression towards a malignant form of the disease.

The individual changes begin with a small disruption at a microenvironmental level. The original arrangement of epithelial cells is highly organized with an apical polarisation in different tissues. There is adherence to the basal lamina, attachment with neighbouring cells, surface proteins are bound to the extracellular matrix, and for each of these interactions there are specialized molecules at play [25]. In the case of the initial steps towards carcinoma, these natural interactions are disrupted and the original arrangement of epithelial cells is altered. Our understanding of the mechanisms responsible is increasing. For example, there are tight junctions between neighbouring cells that provide an adhesive boundary and prevent cell dissociation [26], and hepatocyte growth factor (a cytokine that can be released from stromal cells) disrupts tight junctions in breast cancer cell lines MDA-MB-231 and MCF-7 [26]. This disruption facilitates cell dissociation from the primary site.

A multifactorial cascade of similar changes supports the successful escape of a cell or a cluster from its primary site. We will examine the different features during the metastatic journey of cancer cells from a primary tumour.

\subsection{Departure from the initial location}

The cells leaving the primary tumour lose cell-cell adhesion which can be seen by downregulation of E-cadherin $[27,28]$. Studies have demonstrated loss of E-cadherin through transcriptional repressors including Twist, Snail, and Slug and subsequent promoter hypermethylation [29-32]. Some of these 
factors are predominantly expressed at the invasive front of solid cancers [33], and their expression is controlled by multiple pathways including TGF- $\beta$, EGF, STAT3, and NF- $\kappa$ B [33].

The initial expansion and migration of the malignant cell population is a collective effort. 'Collective cell migration' in biology is generally defined as 'coordinated movement of multiple cells that retain cell-cell contacts while coordinating their actin dynamics and intracellular signalling' [34]. The mechanisms through which this applies in cancer may be more complex and different models have been proposed $[35,36]$. Friedl et al. discuss two morphological and functional variants of collective migration in tumours. The first involves protruding sheets and strands that maintain contact with the primary site while initiating local invasion, and the second involves groups of cells that are completely detached and navigating through the path of least resistance [35]. Different rates and modes of migration have been observed by live intravital imaging using cell lines from solid cancers in xenografts [37-39].

\subsection{Acquisition of the capacity for migration}

Tumours undergo progressive genotypic and phenotypic changes that lead to acquiring the capacity for migration. They activate endogenous gene programs such as that of epithelial-mesenchymal transition (EMT), which reflect changes in normal tissue development and homeostasis [40]. EMT is a biologic process that allows a polarized epithelial cell, which is normally fixed and interacts with basement membrane via its basal surface, to undergo multiple biochemical changes that enable it to assume a mesenchymal cell phenotype, which confers an enhanced migratory capacity, invasiveness, elevated resistance to apoptosis, and greatly increased production of ECM components [41]. While going through this transition, tumour cells with invasive potential lose expression of epithelial markers E-cadherin, epithelial cell adhesion molecule (EpCAM), and cytokeratin [42,43]. At the same time, there is an acquisition of mesenchymal characteristics and expression of cytoskeletal and adhesion proteins such as vimentin, N-cadherin and cellular fibronectin [43]. It is the detection of these proteins that experimentally supports the identification of transition of epithelial to mesenchymal form. Disseminated cancer cells need to self-renew in order to form macroscopic metastases [44]. The process of EMT can be accompanied by the additional advantages of self-renewal capacity and expanded stem-cell like features.

\subsection{Intravasation into blood vessels or lymphatics}

Entry of cancer cells into a blood vessel or lymphatic system is a significant step towards metastasis. Access to the capillaries in the surrounding vicinity creates a favourable environment for the process of intravasation - the process of entry into the blood circulation or lymphatic system [45]. Different stimuli can initiate endothelial activation leading to sprouting of new blood vessels (angiogenesis) and this process can be complicated by mediators which affect the analogous process in lymphatics (lymphangiogenesis) [46]. A co-culture study with tumour cells and lymphatic endothelial cells has explored the role of the lymphangiogenic peptide adrenomedullin (known to be present in many tumours) in the escape of tumour cells into the lymphatic system [47, 48].

The cancer cell has numerous interactions with the extracellular matrix that constrain it from leaving the initial location and moving towards intravasation (Fig. 2A). The same molecular interactions come into play as it enters its metastatic niche, as we will discuss later. The roles of matrix metalloproteinases (MMPs) and specific proteins such as collagen, laminin, and fibronectin have been extensively studied by many groups [49-51]. The variety of interactions discussed in this subsection highlights the complexity that tumour cells face during the initial stages of metastasis, to escape the primary tumour. 

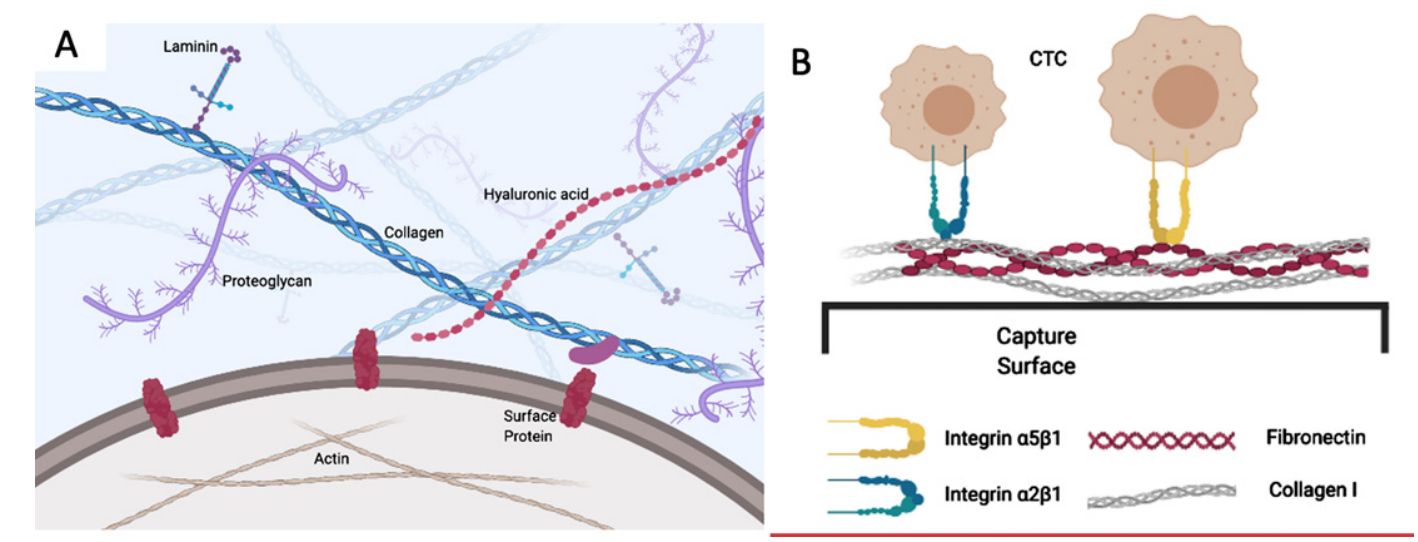

Fig. 2. A) The cancer cell has multiple interactions with ECM ligands through surface receptors such as integrins. These both constrain its initial localization and facilitate its emigration, depending on the nature of the ECM and the regulation of integrins. B) Capture of CTCs using optimized combinations of ECM ligands. CTCs adhere avidly to the mixed ECM substratum through integrins and other cell adhesion receptors that are retained during epithelial-mesenchymal transition, whereas conventional capture molecules that are restricted to epithelial cells, such as EpCAM, may be lost.

\subsection{Definition of a circulating tumour cell (CTC)}

A CTC is broadly defined as a cell that has escaped from a primary tumour (or a metastatic tumour site) and is identifiable in the blood circulation or lymphatic system [52]. The CTC can present itself in many different phenotypes including in a dormant state, mesenchymal or epithelial state, as a stem cell, in a cluster, or any combination of these characteristics [53]. Any cellular fragments such as tumour DNA, mRNA or a ruptured cell that has undergone apoptosis or necrosis would not meet the criteria for a CTC.

A round or oval shape with a cellular diameter from $4 \mu \mathrm{m}$ to occasionally more than $30 \mu \mathrm{m}$ is generally acceptable in CTC studies including the size acceptable with the FDA-approved CellSearch ${ }^{\mathrm{TM}}$ technology $[54,55]$. Definitions of CTCs also include marker-based criteria that accept cells expressing EpCAM, cytokeratins (CKs) 8, 18, and 19, with an absence of the haematopoetic marker CD45 [42, 55].

\subsection{Mechanisms of CTC survival in blood circulation}

The passage through the bloodstream poses a challenge of survival for tumour cells against attack by the immune system and shear forces in the general blood circulation. Cancer cells may acquire unique survival mechanisms that allow them to safely pass through the hostile environment in the blood [56]. They may travel through the circulation in conjunction with blood platelets, and can become capable of escaping immune surveillance by forming tumour cell - platelet aggregates in which the cancer cell is shielded by a peripheral layer of platelets [42] (Fig. 1). Nieswandt et al. used a mouse model to demonstrate that such surface shielding protected tumour cells from lysis by natural killer (NK) cells [57]. Mehta et al. noted an interesting pattern in which osteosarcoma lines induced platelet aggregation, but leukemia nor lymphoma cells did not [58], suggesting that platelet aggregation is more common in non-hematopoietic solid cancers. This may predispose to pulmonary metastasis [58] and in another animal study it was found that mice that are deficient in the platelet-specific receptor glycoprotein IB-alpha (GPIB- $\alpha$ ) exhibited a 15-fold decrease in the formation of lung metastatic foci [59]. Additionally, it is believed that $\alpha$-granule contents released by platelets provide growth-promoting 
factors for tumour development, including vascular endothelial growth factor (VEGF) and transforming growth factor (TGF)- $\beta$ [40]. The aggregation with platelets is supportive for attachment to endothelial cells in microvessels [60]. A study by Weber et al. investigated the interaction between integrin $\alpha \mathrm{v} \beta 3$ on tumour cells and platelets and its consequences for successful transendothelial migration [61].

\subsection{Passage through the blood-CTC clusters}

The process of collective cell migration begun in the exit from the primary tumour continues to some extent in vascular dissemination. Tumour cells have the ability to intravasate and disseminate in the bloodstream as multicellular aggregates or CTC clusters. CTC clusters have been observed in multiple studies across different solid cancers and there is an interest as to whether or not they are associated with stemness, EMT and tumour progression [4, 42, 62, 63]. There is a possibility that these CTC clusters are simply due to the partial shedding of cell clusters from primary tumour emboli or random formation of multicellular aggregates with these clusters being captured at distant sites to proliferate and grow as a consequence purely of their physical size.

The idea that aggregation and associated cellular phenotypic changes influence the metastastic outcome challenges other observations for which metastasis has been fully attributed to EMT or stemness being responsible for the initiation of secondary tumour growth at new sites. In a study by Ye et al. it was noted that E-cadherin expression is elevated in tumour emboli found in lymphovascular regions, and cleavage of E-cadherin may directly initiate the formation of the clusters [64]. The link with E-cadherin may hint towards the involvement of the proteins used as epithelial markers playing a role in the formation of clusters.

Tumour cells moving through the circulation as clusters are certainly more stable and possess survival advantages compared to CTCs moving independently [65]. In clinical settings, it has been observed that CTC clusters are present more frequently when tumour cells display a mesenchymal phenotype [65]. Such an observation opens the gateway to exploring whether initially detached epithelial clusters undergo EMT, or the transformed mesenchymal cells initiate the formation of clusters, perhaps utilizing their association with platelets.

It was initially postulated that CTC clusters are incapable of traversing through smaller capillaries given their larger size. However, studies including that of Au et al. demonstrated that CTC clusters isolated from patients were able to traverse through microfluidic-based capillaries [62]. Au et al. investigated morphological changes such as nuclear deformation and elongation in cluster cells upon encountering capillaries. Cultured CTC clusters were able to transit through constrictions as small as $5 \mu \mathrm{m}$ [62]. Using flow cytometry in an in vivo mouse model, it was observed that the half-life of CTC clusters was approximately $10 \mathrm{~min}$ compared to $30 \mathrm{~min}$ for single CTCs [66]. This could be a result of CTC clusters being trapped in the smaller capillaries earlier than the single CTCs. Au et al. noted that clusters pre-treated with drugs that are known to disrupt cell-cell adhesion resulted in a segregation of cells into singlets or smaller group of cells upon entrance into capillaries [62].

In a recent review, Aceto also describes differences between homotypic and heterotypic CTC clusters and their metastatic potential in comparison to single CTCs [67]. Heterotypic clusters are known to have stromal cells, immune cells, platelets, and endothelial cells in the mixture. From the standpoint of the seed and soil theory [68], having the additional accompanying cells may serve as a soil for the seed (cluster) to better survive in the new microenvironment. There is a study investigating the crosstalk between CTCs and tumour-associated neutrophils (TANs) which demonstrates the metastasispromoting role of neutrophils in the heterotypic clusters [8]. Cytokines IL-6 and ILB1 were frequently implicated in this mediation [69]. Such findings show that further work in this area may lead to deeper understanding of the mechanisms at play and provide therapeutic targets to counter the metastatic activity. 


\subsection{Resistance to the damage by leukocytes}

It is known that tumours formed in mice without an intact immune system are qualitatively different to similar tumours formed in the presence of an intact immune system [70, 71]. The immune system has a detection process known as immune surveillance that constantly identifies cells with potential tumorigenic activity and eradicates many preliminary changes that could pose future clinical threats [72]. Both innate and adaptive arms of the immune system are known to combat tumourigenesis [73]. However, tumour cells have evolved mechanisms to escape immune surveillance and in 2011 Hanahan and Weinberg added 'avoiding immune destruction' as a hallmark of cancer [22].

Tumour cells are able to lower their antigenicity to decrease the recognition by the immune system; altered human leukocyte antigen-I (HLA-1) expression is common in carcinogenesis [74]. Studies have shown partial loss of HLA-1 expression during tumour development and how this poses difficulty for recognition by immune system [75, 76]. Another challenge posed during tumour progression is the release of interferon (IFN)- $\gamma$ by infiltrating lymphocytes, which can increase the expression of immunoinhibitory molecule PD-L1 on the surface of malignant cells [77]. Mazel et al. analyzed CTCs of 16 breast cancer patients (hormone receptor positive and HER2 negative) and found $11(\sim 69 \%)$ patients with PD-L1 expression. Kulasinghe et al. reports a case of a patient with squamous cell carcinoma who had CTC clusters identified with PD-L1 expression [78]. Strati et al. examined 113 head and neck cancer patients and found PD-L1 overexpression in $25.5 \%$ at baseline [79]. In addition, Strati et al. also stratified PD-L1(+) and PD-L1(-) expression amongst the EpCAM(+) fraction and found no difference in the progression-free or overall survival [79]. These examples illustrate the variability and presence of PD-L1 expression across different tumour types. Novel therapeutic treatments targeting PD-L1 have emerged, however it has been recognized that not all tumours expressing PD-L1 respond to the anti-PDL1 therapy [77]. Mechanisms that tumour cells utilize for evasion from the immune system may not be identical across solid cancers and resistance could also be at play [80, 81].

\subsection{Stem cell characteristics}

The two main characteristics of a stem cell population are the ability to self-renew and the capacity to differentiate [82]. Lapidot et al. fractioned acute myeloid leukemia (AML) cells and demonstrated that $\mathrm{CD} 34^{+} \mathrm{CD} 38^{-}$cells were self-initiating and developed leukemia in immunodeficient mice upon engraftment [83]. Stem cell features also include expression of CD44, CD24, CD133, CD166, and ALDH1 as common markers [84]. Other groups confirmed initiation of tumours by such stem cells in various tissues such as breast and brain [85]. There is evidence showing that cancer stem cells (CSCs) also express EMT markers and that the transition from epithelial to mesenchymal phenotype can follow generation of CSCs $[44,86]$. This implicates cellular signalling pathways such as that of Wnt / $\beta$-catenin, which is essential in the stem cell compartments of intestinal crypts and comes into play in many gastrointestinal tumours [87]. The importance of Wnt signalling has also been highlighted in the growth of lung cancer stem cells and expression of pluripotency genes Nanog and Oct 4 [88].

The cell population in the blood circulation may possess stem cell characteristics to enable initiation of growth in secondary locations. Grillet et al. confirmed that certain CTCs isolated from patients possess stem cell characteristics and are able to expand both in vitro and in vivo, exhibiting heterogeneous cell characteristics [89]. Similarly, Soler et al. were able to derive multiple CTC cell lines from a colorectal cancer (CRC) patient that could grow ex vivo for multiple years and that in addition to an EMT phenotype exhibited stem-cell like characteristics [90]. A study by Watanabe et al. was able to correlate the presence of $\mathrm{CD}_{4} 4^{+}$stem cells in gastric cancer with the disease stage, depth of tumour, and venous invasion in resected tumour tissues [91]. Functional studies that look beyond marker expression of CTCs into features such as stemness could have a great value in revealing features 
of CSCs that correlate with success of secondary metastasis. In addition, both EMT and the stemness phenotype can potentially contribute to drug resistance [92]. Conversely, dormancy of metastatic cells is a phenomenon that may underlie therapeutic challenges [93].

\subsection{Extravasation of cells into the secondary tissue}

We have discussed how tumour cell traits such as EMT, stemness, platelet aggregation, cluster formation, and the ability to escape normal immune surveillance contribute to a successful metastatic process. The next issue is understanding how the disseminated cells with these characteristics will behave when they reach individual secondary organs. Diversity in the microenvironment at major secondary sites and the nature of specific tumour cell interactions should identify particular phenotypic features that enable cells to successfully extravasate and establish detectable metastasis.

Extravasation is the process by which cancer cells exit from the circulation into the secondary tissue space. There are variety of ways of modelling this process ranging from in vitro migration and invasion assays using transwells [94] to in vivo models based on the mouse [95] or chick embryo [96]. Using these models, particular mechanisms responsible for successful extravasation can be explored with good resolution as a result of technical advances such as real-time in vivo videomicroscopy [97]. Leong et al. have investigated the involvement of invadopodia and role of molecules such as Tks4 and Tks5 in extravasation using a chick embryo model and videomicroscopy that enable single cell live tracking [98]. Through such studies, specific mechanisms influencing extravasation have been elucidated. For instance, it is evident that extravasation shares features in common with the homing mechanisms of immune cells at the site of inflammation [99]. Indeed, many immune cells actively infiltrate the microenvironment at secondary sites [22]. The competing signalling pathways are complex and beyond the scope of this article.

The secondary site tissue microenvironment is characterized by a unique pattern of pro-tumourigenic molecules [100]. Many of these are chemokines, forming the basis of the receptive 'soil' for the 'seed' of the cancer that has long been suggested [68]. Chemokines are driving factors that dictate the combination of cells that arrive in the tumour microenvironment and may favour or hinder metastatic growth at select secondary sites. Stromal cells in the microenvironment are able to release chemokines that decide the fate of arriving tumour cells. For instance, hepatic stellate cells (HSCs) release chemokines that may promote liver metastasis [101]. Significant amounts of the chemokine SDF-1 (CXCL12) are released by activated HSCs and can promote CXCR4-expressing CRC cells to invade and establish liver metastatic tumours in mice [102].

In order to initiate macrometastases at a secondary site, that will reproduce the full primary cancer histotype, the mesenchymal, stem-like cells surviving the passage through the blood circulation typically revert back to a more characteristic phenotype [43]. A reverse process of mesenchymal-toepithelial transition (MET, Fig. 1) likely takes place at the secondary site and the disseminated cells sequentially proliferate and differentiate to grow into a new tumour tissue that reflects to some degree the character of the primary tumour [44].

\section{Circulating tumour cells and their recovery from blood}

\subsection{The clinical utility of CTCs}

\subsubsection{CTCs as an early detection strategy}

Utilizing CTCs as an early detection strategy is relatively new and there has been some success in certain types of solid cancers. A study by Ilie et al. examined COPD patients who were at high risk of 
developing lung cancer and looked for the presence of CTCs prior to a cancer diagnosis [103]. Five out of 168 COPD patients had positive CTC detection in comparison to the situation for 77 non-COPD patients, for which no CTC were detected in 42 control smokers without a detectable pathology and in 35 non-smoking healthy individuals [103]. The COPD patients with CTC detection were found to have lung nodules (4 adenocarcinomas; 1 squamous cell carcinoma) detected within 1 to 4 years of follow-up, whereas no patients from the control group developed lung nodules or carcinoma [103]. There is also a prognostic potential in biomarkers identified through isolated CTCs. For instance, a clinical trial named COMETI P2 had some initial results indicating that a higher rate of estrogen-positive cells may predict a better response with endocrine treatment, whereas the higher rate of HER2 expression may predict a worse response [104]. A review by Schochter et al. has outlined major CTC biomarker studies in breast cancer and their utility in CTC-based treatment decisions [104]. Arafat et al. have studied HLA and PD-L1 expression from CTCs in the OMNIVORE clinical trial which included metastatic renal cell carcinoma patients progressing on Nivolumab (PD-1 inhibitor) [105]. An international panel of experts has published a consensus statement on circulating biomarkers for advanced prostate cancer [106]. Included in this detailed report is an outline of the unmet needs in development of a circulating biomarker assay for advanced prostate cancer [106]. Specifically, there is a discussion on the androgen receptor splice variant 7 (AR-V7) detection and its association with poor outcome in abiraterone / enzalutamide treatment. It was later established through a study by Scher et al. that there is predictive potential in using AR-V7 marker in metastatic, castration-resistant prostate cancer patients who are treated with taxanes compared to androgen receptor signalling inhibitor (ARSI). Patients who were positive for AR-V7 and received treatment with taxane had a superior overall survival compared to ARSI. It is outside of the scope of this review, but multiple markers and their utility in each type of solid cancer can be mapped to understand the overall implications in prognosis and their influence on treatment decisions.

Going beyond enumeration of CTCs, and tracking their markers, there is also a possibility to harvest and expand the isolated CTCs and clusters ex vivo from each individual to assess their functional properties. Tellez-Gabriel et al. discuss pre-clinical models proposed by different groups working on solid tumours [107]. For instance, Yu et al. explored drug susceptibility of CTC-derived breast cancer cell lines and identified pre-existing mutations that ave clinical importance [108]. Similarly, the study carried out by Zhang et al. showcased ex-vivo expansion of 14 out of 19 lung cancer patient CTC samples, followed by next-generation sequencing which revealed mutations that matched with those of the primary tumour [109]. Gao et al. successfully derived organoid lines from prostate cancer CTC sample and primary tumour biopsies [110]. The mutation profiles identified amongst these organoid lines captured the commonly observed patterns in prostate cancer subtypes, relating to androgen receptor amplification and PTEN deletion [110]. Baccilli et al. utilized xenograft assays to obtain metastasis-initiating cells (MICs) that resulted in multi-organ metastasis in mice [111]. Profiling of the MICs showed correlation between markers such as EPCAM, CD44, CD47, MET and the number of metastatic sites [111]. Hodgkinson et al. isolated CTCs from small cell lung cancer (SCLC) patients and showed that the derived cell lines had similar responses to those that the patients had exhibited upon platinum drug and etoposide treatment [112]. Some of the common challenges encountered in these studies utilizing expansion of cell lines included competing growth of other cells in culture, optimization of growth conditions, alteration of cell characteristics in the new environment, and possible number of passages obtained following expansion. Although further work is required in this area, the studies discussed in this section highlight the utility of CTCs and the potential they hold to personalize therapies in future.

\subsubsection{CTC numbers as a prognostic measure}

Various studies have used the number of CTCs as a predictive biomarker for guiding treatment selection, therapeutic efficacy, and survival expectancy [42, 113-117]. Many have relied on enumeration 
alone to predict prognostic outcomes for solid cancers. Hayes et al. categorized breast cancer samples based on the number of CTCs and assessed the probability of survival [118]. They found that the patient group whose samples had more than 5 CTCs at all time points had the lowest probability of survival compared to the group that had less than 5 CTCs at all time points during the study. There have also been studies that looked at CTC numbers and the progression-free and overall survival in CRC patients; the numerical 'cut-off' for colorectal cancer appears different. Tol et al. divided advanced-stage CRC patients by a CTC count of more than or less than 3 in $7.5 \mathrm{~mL}$ of whole blood [114]. It was found that CTC count prior to and during treatment independently predicted progression-free-survival and overall survival in late-stage CRC patients [114]. Some groups have investigated further to assess whether CTC counts can inform treatment plans. For example, Krebs et al. gathered data that justified the use of four-drug regimen (irinotecan, oxaliplatin, and tegafur-uracil and cetuximab) against advanced colorectal cancer based on the CTC cut-off groups of above and below 3 per sample [113].

\subsubsection{The need to assess CTC-expressed biomarkers}

There are deficiencies in using simple CTC number, and the reliance on this metric has yielded some unexplained results of disease progression that are based on CTC enumeration alone [119]. It has been recognized that there is a greater need to characterize the CTCs periodically for greater clinical value [120]. This may be challenging as any technique that fully or partially relies on a marker for CTC identification might lead to cells being already fixed or punctured for the purpose of marker visualization. As well, relying initially on a particular CTC specific marker could be problematic due to the heterogeneity of isolated cells and genetic instability of tumours [121, 122]. However, if such analysis is successful it can provide valuable information. For instance, Babayan et al. assessed isolated CTCs for estrogen receptor positivity and found that only some cells expressed the protein - perhaps relating to why $20 \%$ of the estrogen targeted therapies can fail [3]. In other cases tissue samples from patient biopsies that were classified as being negative for certain mutations had contrary results when their CTCs were characterized [123, 124]. This may be crucial to understanding metastasis - the EGFR mutation in lung cancer can be different between the primary lesion and the metastatic sites [123].

Following the isolation of CTCs, they could be further characterized for different markers depending on the primary cancer site $[125,126]$. For instance, presence or absence of markers such as EGFR or KRAS can be interesting for solid tumour samples such as from colorectal cancer patients. A study by Fusi et al. isolated melanoma CTCs and analyzed them for expression of chemokine receptors on the surface [127]. There is a commercial test called AdnaTest BreastCancerSelect (Qiagen ${ }^{\mathrm{TM}}$ ) which helps detect CTCs from breast cancer patients' blood samples and characterize them for specific markers including MUCIN-1-EpCAM, ALDH-1, HER2, Twist1, ER, Akt2, and PI3K [128]. Characterization of these markers can be linked to prognosis and help guide treatment decisions.

\subsection{Challenges in CTC isolation}

It is challenging to isolate, characterize and quantify CTCs as they are typically very low in number ( $<10$ CTCs/mL of blood versus millions of nucleated normal white blood cells). In terms of numerical comparison with leukocytes, it is estimated that there is typically about one CTC per million leukocytes [40]. Depending on the subtype of cancer, the probability of detecting CTCs in the blood sample varies substantially. For example, the frequency of detecting CTCs in prostate cancer patients is more than 50\% compared to pancreatic cancer which has a possibility of less than $25 \%$ [42]. This may be explained by the different underlying processes controlling each tumour subtype, the extent of epithelial and mesenchymal characteristics of primary tumor cells, and the type of interactions cancer cells have with the ECM at secondary sites. Once the CTCs are isolated and identified amongst the overall much larger cell population within a blood sample, they can be further characterized. 
There are many different technologies for detecting CTCs from peripheral blood [129-133]. These may be based on the physical characteristics (size, electric potential, density) of cancer cells, or on their biological characteristics (protein expression, functional behavior) and few also use a combination of both (microfluidic chips with capture proteins, filters with antibody tags) [134]. Current commercial CTC-detecting platforms include various forms of magnetic cell sorting, Cell Search ${ }^{\mathrm{TM}}$, $\mathrm{CTC}_{\text {Microseparator }}^{\mathrm{TM}}$, and IsoFlux ${ }^{\mathrm{TM}}$. Using any one of these platforms, it is now possible to define the number of circulating tumour cells by the operational definition within that platform. Ferreira et al. and Joosse et al. have thoroughly reviewed CTC enrichment strategies based on immunoaffinity, biophysical properties, and functional assays [133, 135].

\subsection{Techniques based on microfluidics and charge properties}

Microfluidic technologies have shown promise in efficient capture of CTCs. Combination of the physical and biological properties of CTCs can be utilized to optimize purity of the isolated population. For instance, Zhou et al. utilized size-dependent inertial migration microfluidic system and recovered 93\% of the spiked cancer cells for a concentration of 50 cells or above per $5 \mathrm{~mL}$ of diluted blood [136]. The microchannel approach was also successful in isolating CTCs from 6 out of 8 patients (with a maximum of 78 cells in a patient) and none were detected in the samples of healthy volunteers [136]. Kulasinghe et al. and Warkiani et al. provide examples of spiral microfluidic technology that was used to isolate CTCs from head and neck, advanced breast, and lung cancer patients [137, 138]. Both the groups show a capability of isolating larger cells including Kulasinghe's work that showed cluster isolation. Methodological factors such as use of red-cell lysis, dilution of the whole blood, and flow-rate can affect the yield and purity of the isolated cells.

The work of Ribero-Samy compared the FDA-approved CellSearch ${ }^{\circledR}$ method with their microfluidic system (CROSS chip) utilizing duplicate samples from 9 metastatic colorectal cancer patients [139]. The CROSS chip isolated $>3 \mathrm{CTCs} / 7.5 \mathrm{~mL}$ of whole blood from 7 out of 9 patients, whereas CellSearch ${ }^{\circledR}$ showed no patients with $>3$ CTCs/7.5 mL [139]. Larger scale comparison with CellSearch ${ }^{\circledR}$ in different cancer types can provide further validation of the upcoming microfluidic systems. Other approaches have utilized the electrical charge difference between normal cells and tumour cells in order to isolate the enriched CTC population under an electric field. The DEPArray ${ }^{\mathrm{TM}}$ system partially utilizes microelectrics combined with microfluidics to enrich the CTC population [140]. It utilizes dielectrophoretic force to help separate individual cells.

\subsection{Techniques based on size properties}

Some isolation techniques rely on the biophysical properties of tumour cells, including size, deformability, and cell density, to distinguish CTC from other normal cells in the blood. The challenge with size-based methods is the wide variability of CTC cell size and the frequent size difference between tumour cells from cell lines (on which methods may be optimized) and tumour cells from primary patient samples. A study by Allard et al. noted that CTCs isolated from same patient varied in diameter between 4 and $30 \mu \mathrm{m}$ [141]. Here we describe some of the studies based on size-based methods to appreciate the technical variations, advantages, and limitations with these methods.

Fiorelli et al. showcases a simple method using ScreenCell ${ }^{\circledR}$ with $7.5 \mu \mathrm{m}$ size pores in a polycarbonate membranes in order to isolate CTCs from 81 lung cancer patients [142]. This method uses hematoxylin and eosin staining for characterization, and immunohistochemistry using p63 and TTF-1 antibody for identification of cell origin [142]. Hosokawa et al. reported a size-based microcavity array system in comparison with Cellsearch ${ }^{\circledR}$ for isolation of CTCs from advanced lung cancer patients [143]. They show a significantly higher yield from their microcavity array system in comparison with Cellsearch ${ }^{\circledR}$ 
for both small-cell and non-small-cell lung cancer patient blood samples. Kim et al. utilized a discbased filtration method with liquid-filled pores that help to control the pressure [144]. This device is able to process $3 \mathrm{~mL}$ of whole blood per min without red-cell lysis or prior-dilution. Along with studies using cell lines, they also demonstrated isolation of CTCs from 142 patients including those with breast, stomach, and lung cancers [144]. Different groups utilize additional physical properties such as pressure or electrical field along with size in order to optimize marker-free isolation of CTCs. Au et al. described a combination of microfluidic isolation of cell clusters and single cells by size and asymmetry [145]. They employed a two-stage system that isolates single cells, small and large clusters separately with different size cut-offs. Their staging system has a diameter $\mathrm{x}$ height cut-off at $30 \mu \mathrm{m} \mathrm{x}$ $90 \mu \mathrm{m}$ and this deflects any particles larger than diameter of $30 \mu \mathrm{m}$ - the upper limit of known single cells, for appropriate isolation [141, 145].

One major advantage of size based systems is high-throughput processing of whole blood or diluted blood in a short time-frame of less than $24 \mathrm{~h}$. The Parosortix ${ }^{\mathrm{TM}}$ system is an example of such a technology that uses whole blood for CTC separation and downstream characterization [146]. In contrast, a major disadvantage of size-based methods is the challenge in release and collection of selected cells from the capture cavity for downstream processing. CTCs that are possess deformability properties like leukocytes may be missed depending on the cut-off size of in the techniques [147].

\subsection{Techniques based on immunological markers and affinity procedures}

Flow cytometry can be used to identify different subtypes of cells based on immunological marker expression, and together with sorting can be used in the format of fluorescence-activated cell sorting to permit downstream analysis of isolated cells. Many of the studies undertaken based on immunoidentification utilize standard epithelial markers such as CKs 8,18,19, and EpCAM [42].

The techniques that rely on immunoaffinity can be divided into two broad categories - positive selection and negative selection. EPIC, FASTCell ${ }^{\mathrm{TM}}$, and CytoTrack ${ }^{\mathrm{TM}}$ are examples of positive selection methods as they rely on CK, CD45, and DAPI for identification of CTCs. EasySep ${ }^{\mathrm{TM}}$ offers an option to be used as a negative selection technology and remove the haematopoietic cells from the whole blood sample without requiring prior lysis or density-separation of red blood cells.

Some groups have utilized a multi-pronged approach and combined positive selection techniques with a microfluidic device ${ }^{204}$. Meunier et al. used a combination of size-based filtration and functional antibodies to capture CTCs from spiked blood samples with a high capture efficiency ${ }^{205}$. It is important to note that studies that are solely conducted on spiked blood cells require extension to real patient samples. Some studies have used a combination of CellSearch ${ }^{\mathrm{TM}}$ followed by DEPArray ${ }^{\mathrm{TM}}$ (Menarini Silicone Biosystems) in order to isolate single cells [148, 149].

\subsection{The remaining challenges in CTC isolation}

Many of the studies undertaken so far, and most commercial techniques, isolate CTCs utilizing epithelial markers such as CKs 8, 18 and 19, and EpCAM. Techniques that solely employ epithelial markers such as CK and EpCAM would not detect CTCs that have gone through EMT and therefore predominantly express mesenchymal markers or others acquired in the journey to metastasis [150]. This is an important clinical issue; Yu et al. demonstrated that a dynamic flux between EMT and MET in breast cancer CTCs is detectable and also corresponds with the response to therapy [151]. Quantification of the percentages of mesenchymal and epithelial phenotypes showed that the fraction of mesenchymal CTCs increased with resistance to the targeted therapy [151]. Hence, the phenotypic change in CTCs not only makes detection by conventional methods difficult but is an important clinical aspect that may be overlooked. 


\section{Utilizing the features of CTCs that lead to successful metastasis}

Experimental studies have followed how cells injected into the circulations of chick embryos and mice extravasate and colonise tissues $[152,153]$. Xenografts from isolated CTCs can further provide insight to the functional behaviour of patient-derived cells [154]. The journey that begins at extravasation and culminates in establishment of a successful metastasis has several rate-limiting steps as cells attempt to settle and proliferate in the foreign tissue. Tumour cells arriving at secondary sites are capable of responding to and modulating the microenvironment through secretion of molecules like chemokines and MMPs [155]. Recent research has emphasized the importance of the interactions between the disseminated tumour cells and the cells of the microenvironment at these secondary sites [156]. There is heterogeneity in the microenvironment composition of these various tissues which may preferentially favour certain cells over others. Varying composition of extracellular matrices, the arrangement of endothelial cells and pericytes, a variety of immune system cells, and fenestrations within the endothelium provide different challenges and opportunities for tumour cells arriving at these locations. Tissue-specific cells such as astrocytes in the brain, alveolar cells in the lungs, and Kupffer cells in the liver also add to the complexity of the microenvironment at these sites. It is believed that cells from late-stage disease adapt to the secondary microenvironment differently than those from the primary stage [157]. They may be able to adhere, invade, survive and even proliferate better depending on the interactions that take place. It is these functional and behavioural differences that can be utilized in selectively trapping the invasive circulating tumour cells (CTCs) from peripheral blood.

We will now focus on the key role of the ECM, and how it may be exploited in capture of a wider range of CTCs than single-marker-dependent immunoaffinity methods, as well as tuned to home in on CTCs that have the highest metastatic potential. Some important molecules in the ECM are collagen, fibronectin, laminin, and hyaluronic acid [158]. These structural and functional components of the ECM are recognized by receptors on the cell membrane such as integrins and CD44 [156]. Through modification of these interactions, and the phenomenon that tumour cells can restructure or degrade the ECM [159], invasive cells can proceed towards the site of intravasation. It is known that the breakdown and reorganization of ECM is an important factor for tumour cells to invade through the general tissue matrix and to cross basement membranes [50]. Additionally, interactions of tumour cells with the endothelium are crucial at both steps during intravasation [159] and extravasation [160]. Consequently, changes in these processes may alter the overall rate of metastasis.

\subsection{Functional capture of CTCs through extracellular matrix}

The migrating population of CTCs is complex in terms of CTC clusters and platelet aggregates that may mask particular cellular antigens, as well as factors such as stem-cell-like character and EMT dynamics that affect the particular markers that may be expressed. As indicated earlier, using capture methods that rely on cell markers which may be lost during phenotypic changes like EMT limits retrieval of the full CTC population. Yet it is most important that the CTC population with greatest metastatic potential be recovered for proper assessment. Exploiting ECM protein interactions that the tumour cells naturally engage with in order to traverse through their metastatic journey may be a solution to optimizing the CTC capture, and the choice of ECM component(s) may allow us to focus on those particular cells that have a high probability of successful metastasis (Fig. 2B).

Selected groups have looked at the approach of using ECM to capture CTCs [161-163]. One of the most successful approach has been to lyse the erythrocytes and place the remaining cells on a substratum composed of collagen type I [161]. This may leave a large excess of leukocytes that may subsequently interfere with CTC adherence, and also relies on ligation with a single ECM protein. A more sophisticated approach has been that used by Schneck et al. with an organ-specific platform 
that combines both ECM proteins and organ-specific markers to capture the cell population of interest [164]. It is established that utilizing an ECM platform is a valid strategy for optimally capturing the entire CTC population and provides a minimally-disrupted CTC population for further exploiting the ECM interaction and other properties as functional features of potential prognostic value. Lu et al. demonstrated a collagen-based adhesion matrix to isolate spiked and patient cells from early stage breast cancer patients [165]. In addition to enumeration, they were also able to show correlation of measured frequency of CTCs with staging, lymph node status, and patient survival [165]. For instance, the overall survival was relatively $20 \%$ lower for patients who had $>10$ cells $/ \mathrm{mL}$. The molecular phenotyping further showed a heterogeneous population isolated by this method [165].

Interactions between tumour cell adhesion receptors such as integrins and their ECM ligands are well studied [166-168]. The cancer cells naturally interact with their surroundings and extracellular environment at every stage of their journey on a routine basis. As cancers progress, and as a result of inflammatory influences, there may be increased production of ECM components such as collagen and fibronectin [169], highlighting ligands of particular relevance. These interactions can be exploited ex vivo in capturing CTCs.

It can be hypothesized that for this neoplastic cell population, the addition of fibronectin to a collagen capture substratum (Fig. 2B) is advantageous in that it both increases overall CTC capture and improves recovery of drug-resistant CRC cells that are experimentally more aggressive. In this way, the capture approach can be modified to favour the presumed aggressive or metastasizing cells, essentially reproducing the situation as CTCs interact with ECM proteins in their external environment at secondary sites of metastasis. One potential limitation of this method is consistent preparation of the capture substratum and upscaling for commercial use. However, these challenges can be resolved once pilot studies with patient samples show robust data.

\subsection{ECM capture as a driving strategy for CTC analysis}

The use of ECM to recover CTC from peripheral blood meshes with the biological processes that enable the metastatic process. A study by Pelillo et al. demonstrated that $\alpha 5 \beta 1$ integrin - which binds to fibronectin - plays a role in CRC metastasis into liver tissue [168]. Other cancer cells, such as those of osteosarcoma, show preference for fibronectin binding [170]. There is also evidence to show that $\alpha 2 \beta 1$ receptors on cancer cells participate in interactions with collagen type I [49]. A study by Barbazán et al. demonstrated how interaction of colon cancer cells at the liver endothelium was facilitated by adhesion to vascular fibronectin [171]. Increased ECM production and reduced ECM turnover rate are common in organ fibrosis during cancer progression [172]. The ECM is thus a critical part of the process by which cancer progresses.

Work in recent years has shown that enumeration of CTCs alone may not measure features of the disease that can allow the prediction of disease outcome or inform therapy. It can neither track the more subtle phenotypic changes that occur part-way through the disease nor explain why certain patients relapse. Optimal isolation techniques followed by functional studies that will typically require single-cell or cell-cluster assays will provide better mechanistic insight into the complexity of disease progression.

Whether or not the isolated cells can be put through a subsequent functional assay(s) is a critical aspect for assessing any CTC platform. Many single-cell functional assays and models are described in the literature [155, 173-175]. Single-cell sequencing, single-cell western blot, single-cell proteomics and CyTOF mass cytometry are examples of techniques that will allow for analysis of individual cells post-isolation $[3,176]$. Others have explored carrying out single-cell genomic analysis from isolated CTCs [177]. 
In addition to such broad analyses, many laboratory groups favour approaches that focus in on the receptors, secreted enzymes and released chemokines and other regulatory mediators that may facilitate the establishment of metastases based upon effector cell functions. Di Carlo and colleagues have used a single-cell protease assay to carry out a functional study on single CTCs isolated from prostate cancer to show elevated MMP activity that may correlate with subsequent invasive or other functional activities of the cell [155]. Our interests in CRC and breast cancer focus on the potential cellular interactions through surface peptidases, chemokine receptors and products of metabolism within the hypoxic solid carcinoma environment [178-186]. These factors have significant potential to optimize the existing CTC isolation platforms. Although current platforms carry their limitations, our knowledge of molecular subtypes in different cancers, clinical data, and technical optimizations will lead to identification of tumour specific isolation platforms that hold clinical value and provide an individualized approach for better patient outcomes.

\section{Acknowledgments}

The research undertaken by D.P. has been supported by grants to J.B. from the Canadian Institutes for Health Research (CIHR; FRN 84361), the Natural Sciences and Engineering Research Council of Canada (NSERC; RGPIN 121624), and the University of Waterloo Research Incentive Fund (RIF). J.B. is a Senior Scientist of the Beatrice Hunter Cancer Research Institute. We thank Mala Bahl, MD for continuing support of the clinical experimental work that contributed to D.P.'s project.

\section{Author contributions}

CONCEPTION: JB

DATA CURATION: DP

ANALYSIS OF DATA: DP and JB

PREPARATION OF THE MANUSCRIPT: DP and JB

REVISION FOR IMPORTANT INTELLECTUAL CONTENT: DP and JB

SUPERVISION: JB

\section{Conflict of interest}

Deep Patel has no conflict of interest to report.

Jonathan Blay has no conflict of interest to report.

\section{References}

[1] Dominguez-Vigil IG, Moreno-Martinez AK, Wang JY, Roehrl MHA, Barrera-Saldana HA. The dawn of the liquid biopsy in the fight against cancer. Oncotarget. 2018;9(2):2912-22.

[2] National-Cancer-Institute. NCI Dictionary of Cancer Terms: National Institute of Health; [Available from: https://www.cancer.gov/publications/dictionaries/cancer-terms/def/carcinoma-in-situ.

[3] Heymann D, Tellez-Gabriel M. Circulating Tumor Cells: The Importance of Single Cell Analysis. Adv Exp Med Biol. 2018;1068:45-58.

[4] Aceto N, Bardia A, Miyamoto DT, Donaldson MC, Wittner BS, Spencer JA, et al. Circulating tumor cell clusters are oligoclonal precursors of breast cancer metastasis. Cell. 2014;158(5):1110-22.

[5] Krol I, Castro-Giner F, Maurer M, Gkountela S, Szczerba BM, Scherrer R, et al. Detection of circulating tumour cell clusters in human glioblastoma. Br J Cancer. 2018;119(4):487-91. 
[6] Gkountela S, Castro-Giner F, Szczerba BM, Vetter M, Landin J, Scherrer R, et al. Circulating Tumor Cell Clustering Shapes DNA Methylation to Enable Metastasis Seeding. Cell. 2019;176(1-2):98-112 e14.

[7] Kulasinghe A, Schmidt H, Perry C, Whitfield B, Kenny L, Nelson C, et al. A Collective Route to Head and Neck Cancer Metastasis. Sci Rep. 2018;8(1):746.

[8] Szczerba BM, Castro-Giner F, Vetter M, Krol I, Gkountela S, Landin J, et al. Neutrophils escort circulating tumour cells to enable cell cycle progression. Nature. 2019;566(7745):553-7.

[9] Thress KS, Brant R, Carr TH, Dearden S, Jenkins S, Brown H, et al. EGFR mutation detection in ctDNA from NSCLC patient plasma: A cross-platform comparison of leading technologies to support the clinical development of AZD9291. Lung Cancer. 2015;90(3):509-15.

[10] Hamam R, Hamam D, Alsaleh KA, Kassem M, Zaher W, Alfayez M, et al. Circulating microRNAs in breast cancer: novel diagnostic and prognostic biomarkers. Cell Death Dis. 2017;8(9):e3045.

[11] Whiteside TL. Tumor-Derived Exosomes and Their Role in Cancer Progression. Adv Clin Chem. 2016;74:103-41.

[12] Yamaguchi M, Okamura S, Yamaji T, Iwasaki M, Tsugane S, Shetty V, et al. Plasma cytokine levels and the presence of colorectal cancer. PLoS One. 2019;14(3):e0213602.

[13] Ashworth TR. A Case of Cancer in Which Cells Similar to Those in the Tumours Were Seen in the Blood after Death. The Medical Joural of Australia. 1869(14):146-7.

[14] Patel H, Le Marer N, Wharton RQ, Khan ZA, Araia R, Glover C, et al. Clearance of circulating tumor cells after excision of primary colorectal cancer. Ann Surg. 2002;235(2):226-31.

[15] Mehlen P, Puisieux A. Metastasis: a question of life or death. Nat Rev Cancer. 2006;6(6):449-58.

[16] Guan X. Cancer metastases: challenges and opportunities. Acta Pharm Sin B. 2015;5(5):402-18.

[17] Garcia SB, Novelli M, Wright NA. The clonal origin and clonal evolution of epithelial tumours. Int J Exp Pathol. 2000;81(2):89-116.

[18] Farber E. Cell proliferation as a major risk factor for cancer: a concept of doubtful validity. Cancer Res. 1995;55(17):3759-62.

[19] Evan GI, Vousden KH. Proliferation, cell cycle and apoptosis in cancer. Nature. 2001;411(6835):342-8.

[20] Aggarwal M, Saxena R, Asif N, Sinclair E, Tan J, Cruz I, et al. p53 mutant-type in human prostate cancer cells determines the sensitivity to phenethyl isothiocyanate induced growth inhibition. J Exp Clin Cancer Res. 2019;38(1):307.

[21] Muz B, de la Puente P, Azab F, Azab AK. The role of hypoxia in cancer progression, angiogenesis, metastasis, and resistance to therapy. Hypoxia (Auckl). 2015;3:83-92.

[22] Hanahan D, Weinberg RA. Hallmarks of cancer: the next generation. Cell. 2011;144(5):646-74.

[23] Hanahan D, Weinberg RA. The hallmarks of cancer. Cell. 2000;100(1):57-70.

[24] Bathe OF, Farshidfar F. From genotype to functional phenotype: unraveling the metabolomic features of colorectal cancer. Genes (Basel). 2014;5(3):536-60.

[25] Cancer Invasion and Metastasis: Molecular and Cellular Perspective. [Internet]. Madame Curie Bioscience. 2000-2013 [cited 2020-04-17]. Available from: https://www.ncbi.nlm.nih.gov/books/NBK164700/\#.

[26] Martin TA, Watkins G, Mansel RE, Jiang WG. Hepatocyte growth factor disrupts tight junctions in human breast cancer cells. Cell Biol Int. 2004;28(5):361-71.

[27] Matsumura T, Makino R, Mitamura K. Frequent down-regulation of E-cadherin by genetic and epigenetic changes in the malignant progression of hepatocellular carcinomas. Clin Cancer Res. 2001;7(3):594-9.

[28] Onder TT, Gupta PB, Mani SA, Yang J, Lander ES, Weinberg RA. Loss of E-cadherin promotes metastasis via multiple downstream transcriptional pathways. Cancer Res. 2008;68(10):3645-54.

[29] Shargh SA, Sakizli M, Khalaj V, Movafagh A, Yazdi H, Hagigatjou E, et al. Downregulation of E-cadherin expression in breast cancer by promoter hypermethylation and its relation with progression and prognosis of tumor. Med Oncol. 2014;31(11):250.

[30] Vesuna F, van Diest P, Chen JH, Raman V. Twist is a transcriptional repressor of E-cadherin gene expression in breast cancer. Biochem Biophys Res Commun. 2008;367(2):235-41.

[31] Bolos V, Peinado H, Perez-Moreno MA, Fraga MF, Esteller M, Cano A. The transcription factor Slug represses Ecadherin expression and induces epithelial to mesenchymal transitions: a comparison with Snail and E47 repressors. J Cell Sci. 2003;116(Pt 3):499-511.

[32] Mikami S, Katsube K, Oya M, Ishida M, Kosaka T, Mizuno R, et al. Expression of Snail and Slug in renal cell carcinoma: E-cadherin repressor Snail is associated with cancer invasion and prognosis. Lab Invest. 2011;91(10):1443-58.

[33] Christofori G. New signals from the invasive front. Nature. 2006;441(7092):444-50.

[34] Friedl P, Gilmour D. Collective cell migration in morphogenesis, regeneration and cancer. Nat Rev Mol Cell Biol. 2009;10(7):445-57.

[35] Friedl P, Hegerfeldt Y, Tusch M. Collective cell migration in morphogenesis and cancer. Int J Dev Biol. 2004;48(56):441-9. 
[36] Clark AG, Vignjevic DM. Modes of cancer cell invasion and the role of the microenvironment. Curr Opin Cell Biol. 2015;36:13-22.

[37] Patsialou A, Bravo-Cordero JJ, Wang Y, Entenberg D, Liu H, Clarke M, et al. Intravital multiphoton imaging reveals multicellular streaming as a crucial component of in vivo cell migration in human breast tumors. Intravital. 2013;2(2):e25294.

[38] Pinner S, Jordan P, Sharrock K, Bazley L, Collinson L, Marais R, et al. Intravital imaging reveals transient changes in pigment production and Brn2 expression during metastatic melanoma dissemination. Cancer Res. 2009;69(20):796977.

[39] Geraldo S, Simon A, Elkhatib N, Louvard D, Fetler L, Vignjevic DM. Do cancer cells have distinct adhesions in 3D collagen matrices and in vivo? Eur J Cell Biol. 2012;91(11-12):930-7.

[40] Tannock I, Harrington L, Bristow R, Hill RP. The basic science of oncology. New York: McGraw-Hill; 2013. Available from: http://lib.myilibrary.com?id=513867.

[41] Kalluri R, Weinberg RA. The basics of epithelial-mesenchymal transition. J Clin Invest. 2009;119(6):1420-8.

[42] Friedlander TW, Premasekharan G, Paris PL. Looking back, to the future of circulating tumor cells. Pharmacol Ther. 2014;142(3):271-80.

[43] Lamouille S, Xu J, Derynck R. Molecular mechanisms of epithelial-mesenchymal transition. Nat Rev Mol Cell Biol. 2014;15(3):178-96.

[44] Mani SA, Guo W, Liao MJ, Eaton EN, Ayyanan A, Zhou AY, et al. The epithelial-mesenchymal transition generates cells with properties of stem cells. Cell. 2008;133(4):704-15.

[45] Zavyalova MV, Denisov EV, Tashireva LA, Savelieva OE, Kaigorodova EV, Krakhmal NV, et al. Intravasation as a Key Step in Cancer Metastasis. Biochemistry (Mosc). 2019;84(7):762-72.

[46] Van der Auwera I, Van Laere SJ, Van den Eynden GG, Benoy I, van Dam P, Colpaert CG, et al. Increased angiogenesis and lymphangiogenesis in inflammatory versus noninflammatory breast cancer by real-time reverse transcriptase-PCR gene expression quantification. Clin Cancer Res. 2004;10(23):7965-71.

[47] Karpinich NO, Caron KM. Gap junction coupling is required for tumor cell migration through lymphatic endothelium. Arterioscler Thromb Vasc Biol. 2015;35(5):1147-55.

[48] Karpinich NO, Kechele DO, Espenschied ST, Willcockson HH, Fedoriw Y, Caron KM. Adrenomedullin gene dosage correlates with tumor and lymph node lymphangiogenesis. FASEB J. 2013;27(2):590-600.

[49] Vihinen P, Riikonen T, Laine A, Heino J. Integrin alpha 2 beta 1 in tumorigenic human osteosarcoma cell lines regulates cell adhesion, migration, and invasion by interaction with type I collagen. Cell Growth Differ. 1996;7(4):439-47.

[50] Crotti S, Piccoli M, Rizzolio F, Giordano A, Nitti D, Agostini M. Extracellular Matrix and Colorectal Cancer: How Surrounding Microenvironment Affects Cancer Cell Behavior? J Cell Physiol. 2017;232(5):967-75.

[51] Maity G, Sen T, Chatterjee A. Laminin induces matrix metalloproteinase-9 expression and activation in human cervical cancer cell line (SiHa). J Cancer Res Clin Oncol. 2011;137(2):347-57.

[52] Yang C, Chen F, Wang S, Xiong B. Circulating Tumor Cells in Gastrointestinal Cancers: Current Status and Future Perspectives. Front Oncol. 2019;9:1427.

[53] Christou N, Meyer J, Popeskou S, David V, Toso C, Buchs N, et al. Circulating Tumour Cells, Circulating Tumour DNA and Circulating Tumour miRNA in Blood Assays in the Different Steps of Colorectal Cancer Management, a Review of the Evidence in 2019. Biomed Res Int. 2019;2019:5953036.

[54] Cristofanilli M, Hayes DF, Budd GT, Ellis MJ, Stopeck A, Reuben JM, et al. Circulating tumor cells: a novel prognostic factor for newly diagnosed metastatic breast cancer. J Clin Oncol. 2005;23(7):1420-30.

[55] Chen L, Bode AM, Dong Z. Circulating Tumor Cells: Moving Biological Insights into Detection. Theranostics. 2017;7(10):2606-19.

[56] Rejniak KA. Circulating Tumor Cells: When a Solid Tumor Meets a Fluid Microenvironment. Adv Exp Med Biol. 2016;936:93-106.

[57] Nieswandt B, Hafner M, Echtenacher B, Mannel DN. Lysis of tumor cells by natural killer cells in mice is impeded by platelets. Cancer Res. 1999;59(6):1295-300.

[58] Mehta P, Lawson D, Ward MB, Kimura A, Gee A. Effect of human tumor cells on platelet aggregation: potential relevance to pattern of metastasis. Cancer Res. 1987;47(12):3115-7.

[59] Jain S, Zuka M, Liu J, Russell S, Dent J, Guerrero JA, et al. Platelet glycoprotein Ib alpha supports experimental lung metastasis. Proc Natl Acad Sci U S A. 2007;104(21):9024-8.

[60] Yamauchi K, Yang M, Jiang P, Yamamoto N, Xu M, Amoh Y, et al. Real-time in vivo dual-color imaging of intracapillary cancer cell and nucleus deformation and migration. Cancer Res. 2005;65(10):4246-52.

[61] Weber MR, Zuka M, Lorger M, Tschan M, Torbett BE, Zijlstra A, et al. Activated tumor cell integrin alphavbeta3 cooperates with platelets to promote extravasation and metastasis from the blood stream. Thromb Res. 2016;140(Suppl 1):S27-36. 
[62] Au SH, Storey BD, Moore JC, Tang Q, Chen YL, Javaid S, et al. Clusters of circulating tumor cells traverse capillarysized vessels. Proc Natl Acad Sci U S A. 2016;113(18):4947-52.

[63] Carlsson A, Nair VS, Luttgen MS, Keu KV, Horng G, Vasanawala M, et al. Circulating tumor microemboli diagnostics for patients with non-small-cell lung cancer. J Thorac Oncol. 2014;9(8):1111-9.

[64] Ye Y, Tian H, Lange AR, Yearsley K, Robertson FM, Barsky SH. The genesis and unique properties of the lymphovascular tumor embolus are because of calpain-regulated proteolysis of E-cadherin. Oncogene. 2013;32(13): $1702-13$.

[65] Giuliano M, Shaikh A, Lo HC, Arpino G, De Placido S, Zhang XH, et al. Perspective on Circulating Tumor Cell Clusters: Why It Takes a Village to Metastasize. Cancer Res. 2018;78(4):845-52.

[66] Aceto N, Toner M, Maheswaran S, Haber DA. En Route to Metastasis: Circulating Tumor Cell Clusters and Epithelialto-Mesenchymal Transition. Trends Cancer. 2015;1(1):44-52.

[67] Aceto N. Bring along your friends: Homotypic and heterotypic circulating tumor cell clustering to accelerate metastasis. Biomed J. 2020;43(1):18-23.

[68] Langley RR, Fidler IJ. The seed and soil hypothesis revisited-the role of tumor-stroma interactions in metastasis to different organs. Int J Cancer. 2011;128(11):2527-35.

[69] Guo B, Oliver TG. Partners in Crime: Neutrophil-CTC Collusion in Metastasis. Trends Immunol. 2019;40(7):556-9.

[70] Shankaran V, Ikeda H, Bruce AT, White JM, Swanson PE, Old LJ, et al. IFNgamma and lymphocytes prevent primary tumour development and shape tumour immunogenicity. Nature. 2001;410(6832):1107-11.

[71] Dunn GP, Bruce AT, Ikeda H, Old LJ, Schreiber RD. Cancer immunoediting: from immunosurveillance to tumor escape. Nat Immunol. 2002;3(11):991-8.

[72] Muenst S, Laubli H, Soysal SD, Zippelius A, Tzankov A, Hoeller S. The immune system and cancer evasion strategies: therapeutic concepts. J Intern Med. 2016;279(6):541-62.

[73] Gonzalez H, Hagerling C, Werb Z. Roles of the immune system in cancer: from tumor initiation to metastatic progression. Genes Dev. 2018;32(19-20):1267-84.

[74] Rodriguez JA. HLA-mediated tumor escape mechanisms that may impair immunotherapy clinical outcomes via T-cell activation. Oncol Lett. 2017;14(4):4415-27.

[75] Garrido F, Cabrera T, Concha A, Glew S, Ruiz-Cabello F, Stern PL. Natural history of HLA expression during tumour development. Immunol Today. 1993;14(10):491-9.

[76] Garrido F, Ruiz-Cabello F, Cabrera T, Perez-Villar JJ, Lopez-Botet M, Duggan-Keen M, et al. Implications for immunosurveillance of altered HLA class I phenotypes in human tumours. Immunol Today. 1997;18(2):89-95.

[77] Beatty GL, Gladney WL. Immune escape mechanisms as a guide for cancer immunotherapy. Clin Cancer Res. 2015;21(4):687-92.

[78] Kulasinghe A, Perry C, Kenny L, Warkiani ME, Nelson C, Punyadeera C. PD-L1 expressing circulating tumour cells in head and neck cancers. BMC Cancer. 2017;17(1):333.

[79] Strati A, Koutsodontis G, Papaxoinis G, Angelidis I, Zavridou M, Economopoulou P, et al. Prognostic significance of PD-L1 expression on circulating tumor cells in patients with head and neck squamous cell carcinoma. Ann Oncol. 2017;28(8):1923-33.

[80] O'Donnell JS, Long GV, Scolyer RA, Teng MW, Smyth MJ. Resistance to PD1/PDL1 checkpoint inhibition. Cancer Treat Rev. 2017;52:71-81.

[81] Nowicki TS, Hu-Lieskovan S, Ribas A. Mechanisms of Resistance to PD-1 and PD-L1 Blockade. Cancer J. 2018;24(1):47-53.

[82] Fodde R, Brabletz T. Wnt/beta-catenin signaling in cancer stemness and malignant behavior. Curr Opin Cell Biol. 2007;19(2):150-8.

[83] Lapidot T, Sirard C, Vormoor J, Murdoch B, Hoang T, Caceres-Cortes J, et al. A cell initiating human acute myeloid leukaemia after transplantation into SCID mice. Nature. 1994;367(6464):645-8.

[84] Yang MH, Imrali A, Heeschen C. Circulating cancer stem cells: the importance to select. Chin J Cancer Res. 2015;27(5):437-49.

[85] Li L, Neaves WB. Normal stem cells and cancer stem cells: the niche matters. Cancer Res. 2006;66(9):4553-7.

[86] Krantz SB, Shields MA, Dangi-Garimella S, Munshi HG, Bentrem DJ. Contribution of epithelial-to-mesenchymal transition and cancer stem cells to pancreatic cancer progression. J Surg Res. 2012;173(1):105-12.

[87] Schepers A, Clevers H. Wnt signaling, stem cells, and cancer of the gastrointestinal tract. Cold Spring Harb Perspect Biol. 2012;4(4):a007989.

[88] Zhang X, Lou Y, Wang H, Zheng X, Dong Q, Sun J, et al. Wnt signaling regulates the stemness of lung cancer stem cells and its inhibitors exert anticancer effect on lung cancer SPC-A1 cells. Med Oncol. 2015;32(4):95.

[89] Grillet F, Bayet E, Villeronce O, Zappia L, Lagerqvist EL, Lunke S, et al. Circulating tumour cells from patients with colorectal cancer have cancer stem cell hallmarks in ex vivo culture. Gut. 2017;66(10):1802-10. 
[90] Soler A, Cayrefourcq L, Mazard T, Babayan A, Lamy PJ, Assou S, et al. Autologous cell lines from circulating colon cancer cells captured from sequential liquid biopsies as model to study therapy-driven tumor changes. Sci Rep. 2018;8(1):15931.

[91] Watanabe T, Okumura T, Hirano K, Yamaguchi T, Sekine S, Nagata T, et al. Circulating tumor cells expressing cancer stem cell marker CD44 as a diagnostic biomarker in patients with gastric cancer. Oncol Lett. 2017;13(1):281-8.

[92] Singh A, Settleman J. EMT, cancer stem cells and drug resistance: an emerging axis of evil in the war on cancer. Oncogene. 2010;29(34):4741-51.

[93] Townson JL, Chambers AF. Dormancy of solitary metastatic cells. Cell Cycle. 2006;5(16):1744-50.

[94] Jeon JS, Zervantonakis IK, Chung S, Kamm RD, Charest JL. In vitro model of tumor cell extravasation. PLoS One. 2013;8(2):e56910.

[95] Podsypanina K, Du YC, Jechlinger M, Beverly LJ, Hambardzumyan D, Varmus H. Seeding and propagation of untransformed mouse mammary cells in the lung. Science. 2008;321(5897):1841-4.

[96] Kim Y, Williams KC, Gavin CT, Jardine E, Chambers AF, Leong HS. Quantification of cancer cell extravasation in vivo. Nat Protoc. 2016;11(5):937-48.

[97] Chambers AF, Groom AC, MacDonald IC. Dissemination and growth of cancer cells in metastatic sites. Nat Rev Cancer. 2002;2(8):563-72.

[98] Leong HS, Robertson AE, Stoletov K, Leith SJ, Chin CA, Chien AE, et al. Invadopodia are required for cancer cell extravasation and are a therapeutic target for metastasis. Cell Rep. 2014;8(5):1558-70.

[99] Strell C, Entschladen F. Extravasation of leukocytes in comparison to tumor cells. Cell Commun Signal. 2008;6:10.

[100] Quail DF, Joyce JA. Microenvironmental regulation of tumor progression and metastasis. Nat Med. 2013;19(11): 1423-37.

[101] Kang N, Gores GJ, Shah VH. Hepatic stellate cells: partners in crime for liver metastases? Hepatology. 2011;54(2): 707-13.

[102] Matsusue R, Kubo H, Hisamori S, Okoshi K, Takagi H, Hida K, et al. Hepatic stellate cells promote liver metastasis of colon cancer cells by the action of SDF-1/CXCR4 axis. Ann Surg Oncol. 2009;16(9):2645-53.

[103] Ilie M, Hofman V, Long-Mira E, Selva E, Vignaud JM, Padovani B, et al. "Sentinel” circulating tumor cells allow early diagnosis of lung cancer in patients with chronic obstructive pulmonary disease. PLoS One. 2014;9(10):e111597.

[104] Schochter F, Friedl TWP, deGregorio A, Krause S, Huober J, Rack B, et al. Are Circulating Tumor Cells (CTCs) Ready for Clinical Use in Breast Cancer? An Overview of Completed and Ongoing Trials Using CTCs for Clinical Treatment Decisions. Cells. 2019;8(11).

[105] Arafat W, Desotelle J, Rodems T, McKay RR, Abel J, Choueiri TK, et al. Development and clinical validation of circulating tumor cell (CTC) biomarkers in clear cell renal cell carcinoma (ccRCC) for the OMNIVORE clinical trial. Journal of Clinical Oncology. 2017;35(15_suppl):4579.

[106] Sumanasuriya S, Omlin A, Armstrong A, Attard G, Chi KN, Bevan CL, et al. Consensus Statement on Circulating Biomarkers for Advanced Prostate Cancer. Eur Urol Oncol. 2018;1(2):151-9.

[107] Tellez-Gabriel M, Cochonneau D, Cade M, Jubellin C, Heymann MF, Heymann D. Circulating Tumor Cell-Derived Pre-Clinical Models for Personalized Medicine. Cancers (Basel). 2018;11(1).

[108] Yu M, Bardia A, Aceto N, Bersani F, Madden MW, Donaldson MC, et al. Cancer therapy. Ex vivo culture of circulating breast tumor cells for individualized testing of drug susceptibility. Science. 2014;345(6193):216-20.

[109] Zhang Z, Shiratsuchi H, Lin J, Chen G, Reddy RM, Azizi E, et al. Expansion of CTCs from early stage lung cancer patients using a microfluidic co-culture model. Oncotarget. 2014;5(23):12383-97.

[110] Gao D, Vela I, Sboner A, Iaquinta PJ, Karthaus WR, Gopalan A, et al. Organoid cultures derived from patients with advanced prostate cancer. Cell. 2014;159(1):176-87.

[111] Baccelli I, Schneeweiss A, Riethdorf S, Stenzinger A, Schillert A, Vogel V, et al. Identification of a population of blood circulating tumor cells from breast cancer patients that initiates metastasis in a xenograft assay. Nat Biotechnol. 2013;31(6):539-44.

[112] Hodgkinson CL, Morrow CJ, Li Y, Metcalf RL, Rothwell DG, Trapani F, et al. Tumorigenicity and genetic profiling of circulating tumor cells in small-cell lung cancer. Nat Med. 2014;20(8):897-903.

[113] Krebs MG, Renehan AG, Backen A, Gollins S, Chau I, Hasan J, et al. Circulating Tumor Cell Enumeration in a Phase II Trial of a Four-Drug Regimen in Advanced Colorectal Cancer. Clin Colorectal Cancer. 2015;14(2):115-22 e1-2.

[114] Tol J, Koopman M, Miller MC, Tibbe A, Cats A, Creemers GJ, et al. Circulating tumour cells early predict progressionfree and overall survival in advanced colorectal cancer patients treated with chemotherapy and targeted agents. Ann Oncol. 2010;21(5):1006-12.

[115] de Bono JS, Scher HI, Montgomery RB, Parker C, Miller MC, Tissing H, et al. Circulating tumor cells predict survival benefit from treatment in metastatic castration-resistant prostate cancer. Clin Cancer Res. 2008;14(19):6302-9. 
[116] Smerage JB, Barlow WE, Hortobagyi GN, Winer EP, Leyland-Jones B, Srkalovic G, et al. Circulating tumor cells and response to chemotherapy in metastatic breast cancer: SWOG S0500. J Clin Oncol. 2014;32(31):3483-9.

[117] Lindsay CR, Faugeroux V, Michiels S, Pailler E, Facchinetti F, Ou D, et al. A prospective examination of circulating tumor cell profiles in non-small-cell lung cancer molecular subgroups. Ann Oncol. 2017;28(7):1523-31.

[118] Hayes DF, Cristofanilli M, Budd GT, Ellis MJ, Stopeck A, Miller MC, et al. Circulating tumor cells at each follow-up time point during therapy of metastatic breast cancer patients predict progression-free and overall survival. Clin Cancer Res. 2006;12(14 Pt 1):4218-24.

[119] Lowes LE, Allan AL. Recent advances in the molecular characterization of circulating tumor cells. Cancers (Basel). 2014;6(1):595-624.

[120] Tellez-Gabriel M, Heymann MF, Heymann D. Circulating Tumor Cells as a Tool for Assessing Tumor Heterogeneity. Theranostics. 2019;9(16):4580-94.

[121] Allan AL, Keeney M. Circulating tumor cell analysis: technical and statistical considerations for application to the clinic. J Oncol. 2010;2010:426218.

[122] Hayes DF, Paoletti C. Circulating tumour cells: insights into tumour heterogeneity. J Intern Med. 2013;274(2): $137-43$.

[123] Marchetti A, Del Grammastro M, Felicioni L, Malatesta S, Filice G, Centi I, et al. Assessment of EGFR mutations in circulating tumor cell preparations from NSCLC patients by next generation sequencing: toward a real-time liquid biopsy for treatment. PLoS One. 2014;9(8):e103883.

[124] Somlo G, Lau SK, Frankel P, Hsieh HB, Liu X, Yang L, et al. Multiple biomarker expression on circulating tumor cells in comparison to tumor tissues from primary and metastatic sites in patients with locally advanced/inflammatory, and stage IV breast cancer, using a novel detection technology. Breast Cancer Res Treat. 2011;128(1): $155-63$.

[125] Duffy MJ, McDermott EW, Crown J. Blood-based biomarkers in breast cancer: From proteins to circulating tumor cells to circulating tumor DNA. Tumour Biol. 2018;40(5):1010428318776169.

[126] Economopoulou P, Kotsantis I, Kyrodimos E, Lianidou ES, Psyrri A. Liquid biopsy: An emerging prognostic and predictive tool in Head and Neck Squamous Cell Carcinoma (HNSCC). Focus on Circulating Tumor Cells (CTCs). Oral Oncol. 2017;74:83-9.

[127] Fusi A, Liu Z, Kummerlen V, Nonnemacher A, Jeske J, Keilholz U. Expression of chemokine receptors on circulating tumor cells in patients with solid tumors. J Transl Med. 2012;10:52.

[128] Bulfoni M, Turetta M, Del Ben F, Di Loreto C, Beltrami AP, Cesselli D. Dissecting the Heterogeneity of Circulating Tumor Cells in Metastatic Breast Cancer: Going Far Beyond the Needle in the Haystack. Int J Mol Sci. 2016;17(10).

[129] Tan X, Patil R, Bartosik P, Runnels JM, Lin CP, Niedre M. In Vivo Flow Cytometry of Extremely Rare Circulating Cells. Sci Rep. 2019;9(1):3366.

[130] Bahnassy AA, Saber MM, Mahmoud MG, Abdellateif MS, Abd El-Mooti Samra M, Abd El-Fatah RM, et al. The role of circulating tumor cells in metastatic breast cancer: prognostic and predictive value. Mol Biol Rep. 2018;45(6):2025-35.

[131] Grover PK, Cummins AG, Price TJ, Roberts-Thomson IC, Hardingham JE. Circulating tumour cells: the evolving concept and the inadequacy of their enrichment by EpCAM-based methodology for basic and clinical cancer research. Ann Oncol. 2014;25(8):1506-16.

[132] Kang H, Kim J, Cho H, Han KH. Evaluation of Positive and Negative Methods for Isolation of Circulating Tumor Cells by Lateral Magnetophoresis. Micromachines (Basel). 2019;10(6).

[133] Ferreira MM, Ramani VC, Jeffrey SS. Circulating tumor cell technologies. Mol Oncol. 2016;10(3):374-94.

[134] Yu M, Stott S, Toner M, Maheswaran S, Haber DA. Circulating tumor cells: approaches to isolation and characterization. J Cell Biol. 2011;192(3):373-82.

[135] Joosse SA, Gorges TM, Pantel K. Biology, detection, and clinical implications of circulating tumor cells. EMBO Mol Med. 2015;7(1):1-11.

[136] Zhou J, Kulasinghe A, Bogseth A, O'Byrne K, Punyadeera C, Papautsky I. Isolation of circulating tumor cells in non-small-cell-lung-cancer patients using a multi-flow microfluidic channel. Microsyst Nanoeng. 2019;5:8.

[137] Kulasinghe A, Tran TH, Blick T, O’Byrne K, Thompson EW, Warkiani ME, et al. Enrichment of circulating head and neck tumour cells using spiral microfluidic technology. Sci Rep. 2017;7:42517.

[138] Warkiani ME, Guan G, Luan KB, Lee WC, Bhagat AA, Chaudhuri PK, et al. Slanted spiral microfluidics for the ultra-fast, label-free isolation of circulating tumor cells. Lab Chip. 2014;14(1):128-37.

[139] Ribeiro-Samy S, Oliveira MI, Pereira-Veiga T, Muinelo-Romay L, Carvalho S, Gaspar J, et al. Fast and efficient microfluidic cell filter for isolation of circulating tumor cells from unprocessed whole blood of colorectal cancer patients. Sci Rep. 2019;9(1):8032.

[140] Di Trapani M, Manaresi N, Medoro G. DEPArray system: An automatic image-based sorter for isolation of pure circulating tumor cells. Cytometry A. 2018;93(12):1260-6. 
[141] Allard WJ, Matera J, Miller MC, Repollet M, Connelly MC, Rao C, et al. Tumor cells circulate in the peripheral blood of all major carcinomas but not in healthy subjects or patients with nonmalignant diseases. Clin Cancer Res. 2004;10(20):6897-904.

[142] Fiorelli A, Accardo M, Carelli E, Angioletti D, Santini M, Di Domenico M. Circulating Tumor Cells in Diagnosing Lung Cancer: Clinical and Morphologic Analysis. Ann Thorac Surg. 2015;99(6):1899-905.

[143] Hosokawa M, Kenmotsu H, Koh Y, Yoshino T, Yoshikawa T, Naito T, et al. Size-based isolation of circulating tumor cells in lung cancer patients using a microcavity array system. PLoS One. 2013;8(6):e67466.

[144] Kim TH, Lim M, Park J, Oh JM, Kim H, Jeong H, et al. FAST: Size-Selective, Clog-Free Isolation of Rare Cancer Cells from Whole Blood at a Liquid-Liquid Interface. Anal Chem. 2017;89(2):1155-62.

[145] Au SH, Edd J, Stoddard AE, Wong KHK, Fachin F, Maheswaran S, et al. Microfluidic Isolation of Circulating Tumor Cell Clusters by Size and Asymmetry. Sci Rep. 2017;7(1):2433.

[146] Miller MC, Robinson PS, Wagner C, O'Shannessy DJ. The Parsortix Cell Separation System-A versatile liquid biopsy platform. Cytometry A. 2018;93(12):1234-9.

[147] Sharma S, Zhuang R, Long M, Pavlovic M, Kang Y, Ilyas A, et al. Circulating tumor cell isolation, culture, and downstream molecular analysis. Biotechnol Adv. 2018;36(4):1063-78.

[148] Fernandez SV, Bingham C, Fittipaldi P, Austin L, Palazzo J, Palmer G, et al. TP53 mutations detected in circulating tumor cells present in the blood of metastatic triple negative breast cancer patients. Breast Cancer Res. 2014;16(5):445.

[149] Pestrin M, Salvianti F, Galardi F, De Luca F, Turner N, Malorni L, et al. Heterogeneity of PIK3CA mutational status at the single cell level in circulating tumor cells from metastatic breast cancer patients. Mol Oncol. 2015;9(4):749-57.

[150] Gabriel MT, Calleja LR, Chalopin A, Ory B, Heymann D. Circulating Tumor Cells: A Review of Non-EpCAM-Based Approaches for Cell Enrichment and Isolation. Clin Chem. 2016;62(4):571-81.

[151] Yu M, Bardia A, Wittner BS, Stott SL, Smas ME, Ting DT, et al. Circulating breast tumor cells exhibit dynamic changes in epithelial and mesenchymal composition. Science. 2013;339(6119):580-4.

[152] Koop S, MacDonald IC, Luzzi K, Schmidt EE, Morris VL, Grattan M, et al. Fate of melanoma cells entering the microcirculation: over 80\% survive and extravasate. Cancer Res. 1995;55(12):2520-3.

[153] Goddard ET, Fischer J, Schedin P. A Portal Vein Injection Model to Study Liver Metastasis of Breast Cancer. J Vis Exp. 2016(118).

[154] Que Z, Luo B, Zhou Z, Dong C, Jiang Y, Wang L, et al. Establishment and characterization of a patient-derived circulating lung tumor cell line in vitro and in vivo. Cancer Cell Int. 2019;19:21.

[155] Dhar M, Lam JN, Walser T, Dubinett SM, Rettig MB, Di Carlo D. Functional profiling of circulating tumor cells with an integrated vortex capture and single-cell protease activity assay. Proc Natl Acad Sci U S A. 2018;115(40):9986-91.

[156] Nishida-Aoki N, Gujral TS. Emerging approaches to study cell-cell interactions in tumor microenvironment. Oncotarget. 2019;10(7):785-97.

[157] Fidler IJ. The organ microenvironment and cancer metastasis. Differentiation. 2002;70(9-10):498-505.

[158] Gouirand V, Vasseur S. Fountain of youth of pancreatic cancer cells: the extracellular matrix. Cell Death Discov. 2018;4:1.

[159] Hojilla CV, Wood GA, Khokha R. Inflammation and breast cancer: metalloproteinases as common effectors of inflammation and extracellular matrix breakdown in breast cancer. Breast Cancer Res. 2008;10(2):205.

[160] Mook OR, van Marle J, Jonges R, Vreeling-Sindelarova H, Frederiks WM, Van Noorden CJ. Interactions between colon cancer cells and hepatocytes in rats in relation to metastasis. J Cell Mol Med. 2008;12(5B):2052-61.

[161] Pearl ML, Zhao Q, Yang J, Dong H, Tulley S, Zhang Q, et al. Prognostic analysis of invasive circulating tumor cells (iCTCs) in epithelial ovarian cancer. Gynecol Oncol. 2014;134(3):581-90.

[162] Tulley S, Zhao Q, Dong H, Pearl ML, Chen WT. Vita-Assay Method of Enrichment and Identification of Circulating Cancer Cells/Circulating Tumor Cells (CTCs). Methods Mol Biol. 2016;1406:107-19.

[163] Paris PL, Kobayashi Y, Zhao Q, Zeng W, Sridharan S, Fan T, et al. Functional phenotyping and genotyping of circulating tumor cells from patients with castration resistant prostate cancer. Cancer Lett. 2009;277(2):164-73.

[164] Schneck H, Gierke B, Uppenkamp F, Behrens B, Niederacher D, Stoecklein NH, et al. EpCAM-Independent Enrichment of Circulating Tumor Cells in Metastatic Breast Cancer. PLoS One. 2015;10(12):e0144535.

[165] Lu J, Fan T, Zhao Q, Zeng W, Zaslavsky E, Chen JJ, et al. Isolation of circulating epithelial and tumor progenitor cells with an invasive phenotype from breast cancer patients. Int J Cancer. 2010;126(3):669-83.

[166] Lovitt CJ, Shelper TB, Avery VM. Doxorubicin resistance in breast cancer cells is mediated by extracellular matrix proteins. BMC Cancer. 2018;18(1):41.

[167] Lu P, Weaver VM, Werb Z. The extracellular matrix: a dynamic niche in cancer progression. J Cell Biol. 2012;196(4):395-406.

[168] Pelillo C, Bergamo A, Mollica H, Bestagno M, Sava G. Colorectal Cancer Metastases Settle in the Hepatic Microenvironment Through alpha5beta1 Integrin. J Cell Biochem. 2015;116(10):2385-96. 
[169] Cox TR, Erler JT. Remodeling and homeostasis of the extracellular matrix: implications for fibrotic diseases and cancer. Dis Model Mech. 2011;4(2):165-78.

[170] Hsiao CT, Cheng HW, Huang CM, Li HR, Ou MH, Huang JR, et al. Fibronectin in cell adhesion and migration via N-glycosylation. Oncotarget. 2017;8(41):70653-68.

[171] Barbazan J, Alonso-Alconada L, Elkhatib N, Geraldo S, Gurchenkov V, Glentis A, et al. Liver Metastasis Is Facilitated by the Adherence of Circulating Tumor Cells to Vascular Fibronectin Deposits. Cancer Res. 2017;77(13):3431-41.

[172] Frantz C, Stewart KM, Weaver VM. The extracellular matrix at a glance. J Cell Sci. 2010;123(Pt 24):4195-200.

[173] Cheng YH, Chen YC, Lin E, Brien R, Jung S, Chen YT, et al. Hydro-Seq enables contamination-free high-throughput single-cell RNA-sequencing for circulating tumor cells. Nat Commun. 2019;10(1):2163.

[174] D'Avola D, Villacorta-Martin C, Martins-Filho SN, Craig A, Labgaa I, von Felden J, et al. High-density single cell mRNA sequencing to characterize circulating tumor cells in hepatocellular carcinoma. Sci Rep. 2018;8(1):11570.

[175] Fior R, Povoa V, Mendes RV, Carvalho T, Gomes A, Figueiredo N, et al. Single-cell functional and chemosensitive profiling of combinatorial colorectal therapy in zebrafish xenografts. Proc Natl Acad Sci U S A. 2017;114(39): E8234-E43.

[176] Budnik B, Levy E, Harmange G, Slavov N. SCoPE-MS: mass spectrometry of single mammalian cells quantifies proteome heterogeneity during cell differentiation. Genome Biol. 2018;19(1):161.

[177] Thiele JA, Pitule P, Hicks J, Kuhn P. Single-Cell Analysis of Circulating Tumor Cells. Methods Mol Biol. 2019;1908:243-64.

[178] Blay J, White TD, Hoskin DW. The extracellular fluid of solid carcinomas contains immunosuppressive concentrations of adenosine. Cancer Res. 1997;57(13):2602-5.

[179] Cutler MJ, Lowthers EL, Richard CL, Hajducek DM, Spagnuolo PA, Blay J. Chemotherapeutic agents attenuate CXCL12-mediated migration of colon cancer cells by selecting for CXCR4-negative cells and increasing peptidase CD26. BMC Cancer. 2015;15:882.

[180] Hoskin DW, Mader JS, Furlong SJ, Conrad DM, Blay J. Inhibition of T cell and natural killer cell function by adenosine and its contribution to immune evasion by tumor cells (Review). Int J Oncol. 2008;32(3):527-35.

[181] Hoskin DW, Reynolds T, Blay J. Adenosine as a possible inhibitor of killer T-cell activation in the microenvironment of solid tumours. Int J Cancer. 1994;59(6):854-5.

[182] MacKenzie WM, Hoskin DW, Blay J. Adenosine inhibits the adhesion of anti-CD3-activated killer lymphocytes to adenocarcinoma cells through an A3 receptor. Cancer Res. 1994;54(13):3521-6.

[183] Mujoomdar M, Bennett A, Hoskin D, Blay J. Adenosine stimulation of proliferation of breast carcinoma cell lines: evaluation of the $[3 \mathrm{H}]$ thymidine assay system and modulatory effects of the cellular microenvironment in vitro. J Cell Physiol. 2004;201(3):429-38.

[184] Mujoomdar M, Hoskin D, Blay J. Adenosine stimulation of the proliferation of colorectal carcinoma cell lines. Roles of cell density and adenosine metabolism. Biochem Pharmacol. 2003;66(9):1737-47.

[185] Richard CL, Tan EY, Blay J. Adenosine upregulates CXCR4 and enhances the proliferative and migratory responses of human carcinoma cells to CXCL12/SDF-1alpha. Int J Cancer. 2006;119(9):2044-53.

[186] Tan EY, Mujoomdar M, Blay J. Adenosine down-regulates the surface expression of dipeptidyl peptidase IV on HT-29 human colorectal carcinoma cells: implications for cancer cell behavior. Am J Pathol. 2004;165(1):319-30.

[187] Chaffer CL, Weinberg RA. A perspective on cancer cell metastasis. Science. 2011;331(6024):1559-64. 